\title{
O imposto territorial rural e os municípios:o impacto nas receitas municipais e a renúncia fiscal
}

\author{
The rural territorial tax and the villages: the impact on the municipal collections \\ and the tax renunciation
}

\author{
José Gilberto de Souza ${ }^{1}$
}

\section{RESUMO}

O artigo reúne uma análise do impacto da arrecadação do Imposto Territorial Rural no período de 1995 a 1997 nos municípios paulistas de Bragança Paulista, Franca e Porto Ferreira frente à composição das receitas municipais. A análise é realizada com base nas legislações do imposto vigentes no período e realiza comparações de arrecadação e projeções tendo como referência os valores da terra nua arbitrados pela Secretaria da Receita Federal (SRF) e pesquisados pelo Instituto de Economia Agrícola da Secretaria de Estado dos Negócios da Agricultura e Abastecimento de São Paulo. Os resultados da pesquisa indicam percentuais de evasão fiscal que atingiram de $18 \%$ a $52 \%$ e inadimplência de até $31 \%$ e esse perfil de evasão se acentua quando a partir de 1996 a SRF deixa de estabelecer o valor da terra nua mínimo (VTNm) e passa a tomar como referência apenas os valores declarados pelo contribuinte.

Palavras-chave: imposto territorial rural, evasão fiscal, política fiscal, política agrária.

\section{ABSTRACT}

The paper brings an analysis about the impact of the Rural Territorial Tax on the composition of the municipal taxes, during the period 1995-1997, in the villages Bragança Paulista, Franca e Porto Ferreira, of the São Paulo state. The work was done based on the tax legislation in that period and compares collections and projections according to the values of the land without any agricultural utilization, cited by Agricultural Economy Institute and supplying Secretary of São Paulo, and indicates the profiles of tax evasion when the Federal Collections Secretary doesn't establish the minimum value of the land without agricultural utilization to be declared by contributor.

Key words: rural territorial tax, tax evasion, agrarian politics, tax politics.

\section{INTRODUÇÃO}

O Imposto Territorial Rural (ITR) passou à esfera federal no ano de 1964, pela emenda de 10 de novembro, ainda que mantendo parte do resultado de sua arrecadação junto aos municípios por meio de transferências constitucionais, (VILARINHO, 1989; ARAÚJO, 1972). As questões da descentralização do tributo e sua importância na composição das receitas públicas são retomadas no debate da reforma fiscal que ocupou o cenário político brasileiro nos últimos anos (JOBIM, et al, 1995; KANDIR, 1995; REZENDE, 1995; INTERNATIONAL MONETARY FUND, 1992) quando tais propostas ganharam evidência (SOUZA, 1995). Propõe-se, neste artigo, estabelecer uma análise do Imposto Territorial Rural verificando seus impactos nas receitas públicas municipais e projetando índices de inadimplência e evasão fiscal no período de 1995 a 1997, que compreende a implantação de duas legislações do tributo, a Lei 8847/94 e a Lei 9393/96, esta última que ao alterar as alíquotas recebe fortes pressões do setor fundiário brasileiro no sentido de que a Secretaria da Receita Federal (SRF) revisasse o Valor da Terra Nua mínimo (VTNm) aplicado, gerando significativo número de demandas judiciais sobre os valores arbitrados.

\section{MATERIAL E MÉTODOS}

As investigações foram realizadas junto aos municípios paulistas de Bragança Paulista, Franca

${ }^{1}$ Geógrafo, Professor, Doutor do Curso de Pós-graduação em Zootecnia da Faculdade de Ciências Agrárias e Veterinárias, Universidade Estadual Paulista (UNESP), Departamento de Economia Rural, 14870-000, Jaboticabal, SP. E-mail: jgilbert@fcav.unesp.br 
e Porto Ferreira. Destaca-se que os dados apresentados referentes ao Imposto Territorial têm como fonte a Secretaria do Tesouro Nacional (STN) (1999) e são relativos às transferências constitucionais, comparecendo, portanto, como fluxo de caixa do tributo naquele ano e não os valores arrecadados no ano de exercício fiscal, uma vez que os dados, ou melhor, os valores do exercício fiscal, correspondem aos valores de transferência da STN.

Esta diferença é o tempo transcorrido entre os vencimentos da primeira à quarta parcela ou parcela única do ITR, lançada ou declarada no ano de exercício até a primeira data de vencimento do imposto relativo ao ano fiscal subseqüente. Significa dizer que os valores computados correspondem ao exercício fiscal, sendo possível que estejam agregados a estes valores parcelas dos anos anteriores que, porventura, tenham sido recolhidas em atraso.

Alerta-se que, diante da imprecisão das datas bases de lançamento dos lotes de cobrança da SRF, manteve-se como referência as transferências constitucionais, uma vez que, no período, os valores seriam agregados. Por outro lado, ao agregar os valores transferidos nos anos de 1995, 1996 e 1997 e comparar com as somas dos meses de transferência, informados pela STN (1999), de setembro de 1995 até outubro de 1998, obtêm-se valores correntes muito próximos aos transferidos.

No segundo momento, são realizadas projeções de arrecadação por meio de análises de preços de terras, aplicando alíquotas médias sobre estes valores e taxações das legislações vigentes no período com base nos dados do Levantamento das Unidades de Produção Agropecuária do estado de São Paulo - LUPA (PINO, 1996) e dos preços de terra nua arbitrados pela SRF, para o ano de 1996, e em relação aos preços detectados pelo Instituto de Economia Agrícola (IEA) da Secretaria de Estado dos Negócios da Agricultura e Abastecimento de São Paulo (SAASP) para o mesmo período. As análises são baseadas nas medianas de preços e tendo como pressuposto que todos os proprietários utilizaram suas terras num percentual superior a $80 \%$, estando, portanto, sujeitos às alíquotas mínimas destas legislações. Estes procedimentos foram adotados a fim de que se obtivesse uma margem de segurança com relação aos índices apontados.

Foram utilizadas as seguintes categorias de uso do solo para o cálculo do tributo: área total da propriedade, áreas com culturas perenes, semiperene e anual, com pastagem, reflorestamento e vegetação natural. Área inaproveitada compreende as terras não utilizadas, mas que apresentam potencial para tanto. A área inaproveitável compreende as terras que não podem ser utilizadas para atividades agropecuárias. A área complementar compreende aquelas ocupadas com benfeitorias (casas, currais, etc.), bem como estradas, açudes, lagos e similares, ou simplesmente, a área faltante para completar a área total da Unidade de Produção Agropecuária (UPA), considerada como não tributável. Estes dados foram calculados para cada UPA com o objetivo de cálculo do grau de utilização da terra $(\mathrm{GU})$, que foram agregados por classe de área, de acordo com as legislações do ITR (Leis 8847/94 e 8393/96). No cálculo de cada UPA se adotou os seguintes procedimentos:

Área Isenta $(\mathrm{AI})=$ Vegetação Natural + Inaproveitável + Complementar

Área Utilizada $(\mathrm{AU})=$ Área Total $-($ Área

Isenta + Inaproveitável)

Área de Cálculo/Tributável $(\mathrm{AC})$ = Área

Total - Área Isenta (AI)

Grau de utilização $\mathrm{GU}=\underline{\mathrm{AU}} \%$

Os dados permitiram apontar para as situações de arrecadação do tributo nos municípios. Nesse caso, foi necessário apontar a área tributável e o valor da terra nua, tendo sido utilizado no exemplo abaixo o VTNm arbitrado pela SRF para o ano de 1996 (Conforme a Lei 8847/94):

a) Área Tributável - Identificou-se como área tributável todas as propriedades rurais (estabelecimentos agropecuários) identificados como UPA, no levantamento realizado no ano de 1996 pela SAA-SP, excluídas as áreas cujo uso ou ocupação fosse identificado com as seguintes categorias: vegetação natural, inaproveitável e complementar;

b) Valor das Terras Tributadas - Utilizouse os valores apontados na pesquisa do IEA, tendo como data de referência o mês de novembro de cada ano, aplicado como valor para o ano subseqüente o que permitiu realizar cálculos para identificação do valor a ser arrecadado. Destaca-se que a legislação do ITR apresentou para os anos de 1994, 1995, e 1996, o lançamento do valor mínimo da terra nua por ha em todos os municípios brasileiros. Nesse caso, na realização dos cálculos, indicou-se o valor da terra nua da SRF e o valor apontado pela pesquisa anual do IEA.

Os cálculos para a composição do valor do imposto (VITR) foram realizados de acordo com as legislações e tendo por base os dados de GU, apurados junto ao LUPA/IEA por classe de área, conforme o exemplo abaixo com base na Lei 8847/ 94, em que a segunda classe de área é de 25 a 50 ha, 
alíquota de $0,03 \%$ e com o Valor da Terra Nua Mínimo (VTNm) arbitrado pela SRF no valor de R\$1.773,33, no município de Bragança Paulista-SP:

$\mathrm{AC}=2.926,5$ ha $-\mathrm{GU}=99,9 \%$.

AC. VTNm . 0,03\% = VITR

$2.926,5 \times 1.773,33=\mathrm{R} \$ 5.189 .650,24 \times 0,03 \%=\mathrm{VITR}$ $=\mathrm{R} \$ 1.556,89$

a) O VITR a ser arrecadado junto as propriedades de 0 a 50ha é de $R \$ 1.556,89$. Observando que, nessa pesquisa, todas as propriedades com menos de 25 ha foram excluídas da área tributável (AC), garantindo que as projeções estão seguras quanto ao número de propriedades consideradas isentas.

\section{RESULTADOS}

Impactos do Imposto Territoria Rural ( ITR), nas receitas municipais

No caso de Bragança Paulista (Tabela 1) observa-se que no conjunto das receitas municipais, houve uma evolução na arrecadação, sendo mais significativos os aumentos do IPTU (143\%) em relação ao ano base de 1995 e do ITR com um aumento de $834 \%$ no ano de 1996 , com decréscimo no ano seguinte (400\%), mas tal evolução foi pouco impactante no conjunto das receitas territoriais (próprias) do município que permaneceram no período em torno de $10 \%$ de participação no total, evidenciando maior atuação fiscal na base tributária territorial urbana.

O município de Franca no que se refere às transferências do ITR, também não se diferencia, apresentando evolução e recrudescimento no período. Tal dinâmica é marcada pela legislação alterada no período. Neste caso, em particular, há evidências de que a legislação de 1994, ao arbitrar o VTNm, promoveu impactos fiscais significativos. Do ponto de vista das receitas próprias, principalmente o IPTU, esse município apresentou menor crescimento no período (119\%), contrastando com os $143 \%$ e $137 \%$, de Bragança Paulista e Porto Ferreira, respectivamente, (Tabela 1). Da mesma forma, as receitas territoriais, em seu conjunto, também diminuíram a participação nas receitas totais em torno de um ponto percentual.

O município de Porto Ferreira apresentou resultado muito próximo ao de Bragança Paulista em termos percentuais. Destaca-se que as alterações no ITR e o crescimento constante do IPTU são pouco representativos no total das receitas municipais. As receitas territoriais oscilaram o percentual de participação reduzindo-o no final do período. Apresenta-se o ITR, na composição das receitas próprias, com valores que não atingem $0,05 \%$ da receita total.
Os dados consolidados na Tabela 1 revelam que o "esforço" do governo federal na fiscalização desse imposto foi pouco impactante. Apenas no período de mudança da legislação a sociedade recebia diretamente informações acerca do comportamento do setor fundiário, em relação ao ITR, quando se concentraram os esforços de fiscalização (FARIAS, 1994). Mesmo nas receitas municipais os valores arrecadados e transferidos são pouco significativos, revelando que, apesar da alteração promovida na legislação tributária do imposto territorial rural, as alíquotas praticadas são reduzidas.

Legislações recentes do Imposto Territoria Rural (ITR) - projeções de arrecadação

Nessa seção, apresenta-se exercícios de simulação de preços de terras objetivando: a) apontar a relação entre os valores absolutos do período e sua variação face ao comportamento dos preços dos imóveis; b) projeções de tributação diante das duas legislações mais recentes com base nos dados do LUPA e dos preços de terra nua, arbitrado pela SRF, para o ano de 1996, e em relação aos preços detectados pelo IEA no mesmo período. Apresenta-se, portanto, o valor de ITR (VITR) nas seguintes situações para cada ano dos municípios de acordo com as legislações 9.393/96 e 8.847/94: com base no VTNm arbitrado pela SRF e VTN apurado pelo IEA.

Em Bragança Paulista, observa-se que os índices de arrecadação das legislações apresentaram um VTNm arbitrado pela SRF muito reduzido o que não permitiu projetar um percentual de inadimplência, uma vez que a redução da VTNm apresentou uma redução do valor em torno de 52,82\%. (Tabela 2). Por outro lado, não se pode apontar para este município um índice de evasão fiscal tendo em vista que: a) a exclusão das propriedades com menos de 30 há, diante da não identificação de titularidade, utilizada como critério na metodologia, atingiu de forma significativa a base tributável, pois corresponde a aproximadamente $20 \%$ da área total, a segunda maior classe de área do município; b) os valores apurados pelo IEA tomam a região do Escritório de Desenvolvimento Rural como área homogênea, forçando para baixo os valores de terra nua do município sede da EDR que apresenta uma estrutura urbana consolidada que tendencialmente flexiona os preços das terras rurais para cima.

Por sua vez, na tabela 3 , ao indicar o número total de hectares e a área tributável que atinge o percentual de $71,3 \%$ da área total do município, percebe-se a possibilidade de aumento na área 
Tabela 1 - Transferências em valores absolutos e índices (1995=100), percentuais de participação do ITR e somatória dos e tributos prediais territoriais municípios de Bragança Paulista, Franca e P. Ferreira - SP (1995-1997)

\begin{tabular}{|c|c|c|c|c|c|c|c|c|c|}
\hline \multicolumn{10}{|c|}{ Bragança Paulista } \\
\hline \multirow[t]{3}{*}{ Imposto } & \multicolumn{2}{|l|}{1995} & \multicolumn{3}{|l|}{1996} & \multicolumn{4}{|l|}{1997} \\
\hline & Valor(R\$) & Índice & $\%$ & Valor $(\mathrm{R} \$)$ & Índice & $\%$ & Valor(R\$) & Índice & $\%$ \\
\hline & & & \multicolumn{3}{|l|}{ Part. } & \multicolumn{3}{|l|}{ Part. } & Part. \\
\hline Arrecadação total & $37.659 .567,00$ & 100 & - & $46.294 .258,00$ & 122 & - & $\begin{array}{l}51.125 .729 \text {, } \\
00\end{array}$ & 135 & - \\
\hline Outras rec. próprias & $4.836 .834,00$ & 100 & 12,84 & $6.203 .663,00$ & 128 & 13,40 & $\begin{array}{l}6.483 .865,0 \\
0\end{array}$ & 134 & 12,68 \\
\hline IPTU & $3.804 .563,00$ & 100 & 10,10 & $4.964 .125,00$ & 130 & 10,72 & $\begin{array}{l}5.454 .792,0 \\
0\end{array}$ & 143 & 10,67 \\
\hline ITR.transferido & $6.045,00$ & 100 & 0,01 & $50.466,00$ & 834 & 0,11 & $24.184,00$ & 400 & 0,05 \\
\hline ITR. arrec.exercício & $53.076,16$ & & & $24.916,89$ & & & $62.656,89$ & & \\
\hline T. tributos territoriais & $3.810 .608,00$ & 100 & 10,11 & $5.014 .591,00$ & 131 & 10,83 & $\begin{array}{l}5.478 .976,0 \\
0\end{array}$ & 143 & 10,72 \\
\hline \multicolumn{10}{|c|}{ Franca } \\
\hline & Valor(R\$) & Índice & $\%$ & Valor(R\$) & Índice & $\%$ & Valor(R\$) & Índice & $\%$ \\
\hline & & & Part. & & & Part. & & & Part. \\
\hline Arrecadação total & $59.356 .767,00$ & 100 & - & $74.683 .160,82$ & 125 & - & $\begin{array}{l}88.082 .405, \\
71\end{array}$ & 148 & - \\
\hline Outras rec. próprias & $15.084 .651,93$ & 100 & 25,41 & $15.465 .160,08$ & 102 & 20,71 & $\begin{array}{l}14.732 .768 \\
81\end{array}$ & 97 & 16,73 \\
\hline IPTU & $4.643 .286,40$ & 100 & 7,82 & $5.571 .240,04$ & 119 & 7,46 & $\begin{array}{l}5.549 .616,2 \\
1\end{array}$ & 119 & 6,30 \\
\hline ITR.transferido & $3.567,61$ & 100 & 0,01 & $37.906,87$ & 1062 & 0,05 & $19.220,71$ & 538 & 0,02 \\
\hline ITR. arrecad. exercício & $21.919,23$ & & & $14.276,96$ & & & $36.038,78$ & & \\
\hline T. tributos territoriais & $4.646 .854,01$ & 100 & 7,83 & $5.609 .146,91$ & 102 & 7,51 & $\begin{array}{l}5.568 .936,9 \\
2\end{array}$ & 119 & 6,32 \\
\hline \multicolumn{10}{|c|}{ Porto Ferreira } \\
\hline & Valor(R\$) & Índice & $\%$ & Valor(R\$) & Índice & $\%$ & Valor(R\$) & Índice & $\%$ \\
\hline & & & Part. & & & Part. & & & Part. \\
\hline Arrecadação total & $12.814 .127,85$ & 100 & - & $15.148 .437,96$ & 118 & - & $\begin{array}{l}17.783 .848, \\
11\end{array}$ & 139 & - \\
\hline Outras rec. próprias & $2.233 .838,08$ & 100 & 17,43 & $2.515 .407,40$ & 113 & 16,61 & $\begin{array}{l}3.595 .630,4 \\
8\end{array}$ & 161 & 20,22 \\
\hline IPTU & $948.893,38$ & 100 & 7,40 & $1.144 .746,66$ & 121 & 7,56 & $\begin{array}{l}1.295 .579,9 \\
5\end{array}$ & 137 & 7,29 \\
\hline ITR. transferido & $1.827,40$ & 100 & 0,01 & $19.395,88$ & 1061 & 0,13 & $7.910,21$ & 433 & 0,04 \\
\hline ITR. arrecad. exercício. & $11.223,40$ & & & $14.051,33$ & & & $17.952,49$ & & \\
\hline T. tributos territoriais & $950.720,78$ & 100 & 7,41 & $1.164 .142,54$ & 122 & 7,69 & $\begin{array}{l}1.303 .490,1 \\
6\end{array}$ & 137 & 7,33 \\
\hline \multicolumn{10}{|c|}{ Consolidados } \\
\hline & Valor(R\$) & Índice & $\%$ & Valor(R\$) & Índice & $\%$ & Valor(R\$) & Índice & $\%$ \\
\hline & & & Part. & & & Part. & & & Part. \\
\hline Arrecadação total & $109.830 .461,85$ & 100 & - & $\begin{array}{l}136.125 .856,7 \\
8\end{array}$ & 123 & - & $\begin{array}{l}156.991 .98 \\
2,82\end{array}$ & 142 & - \\
\hline Outras rec. próprias & $22.155 .324,01$ & 100 & 20,17 & $24.184 .230,48$ & 109 & 17,76 & $\begin{array}{l}24.812 .264 \\
29\end{array}$ & 102 & 15,47 \\
\hline IPTU & $9.573 .412,29$ & 100 & 8,71 & $11.680 .111,70$ & 122 & 8,58 & $\begin{array}{l}12.299 .988, \\
16\end{array}$ & 105 & 7,83 \\
\hline ITR. Transferido & $11.440,01$ & 100 & 0,10 & $107.768,75$ & 942 & 0,79 & $51.314,92$ & 47 & 0,32 \\
\hline ITR. arrecad. Exercício & $86.218,79$ & & & $53.245,18$ & & & $116.648,16$ & & \\
\hline T. tributos territoriais & $9.584 .852,30$ & 100 & 8,72 & $11.787 .880,45$ & 122 & 8,59 & $\begin{array}{l}\text { 12.351.303, } \\
08\end{array}$ & 104 & 7,86 \\
\hline
\end{tabular}

Fonte: Secretaria do Tesouro Nacional -STN (1999)/ PINO (1996) /Dados da pesquisa, 1998. 
Tabela 2 - Transferência do imposto territorial rural (ITR), hectares totais e tributáveis - municípios de Bragança Paulista, Franca e Porto Ferreira - 1995/1998 (R\$)

\begin{tabular}{|c|c|c|c|c|}
\hline \multicolumn{5}{|c|}{ Bragança Paulista } \\
\hline & 1995 & 1996 & 1997 & 1998 \\
\hline Arrecadação ITR & $6.571,66$ & $51.780,39$ & $24.074,54$ & $62.555,84$ \\
\hline Hectares totais & $34.165,90$ & $34.165,90$ & $34.165,90$ & $34.165,90$ \\
\hline Hectares tributáveis ${ }^{(1)}$ & $25.240,4^{*}$ & $24.345,70 * *$ & $24.345,70 * *$ & $24.345,70 * *$ \\
\hline Valor médio p/ há/ano (1X2) (50\% Transf) & 0,52 & 4,26 & 1,98 & 5,14 \\
\hline \multicolumn{5}{|c|}{ Franca } \\
\hline & 1995 & 1996 & 1997 & 1998 \\
\hline Arrecadação ITR & $3.567,61$ & $28.280,24$ & $7.649,66$ & $35.504,20$ \\
\hline Hectares totais & $41.490,90$ & $41.490,90$ & $41.490,90$ & $41.490,90$ \\
\hline Hectares tributáveis ${ }^{(2)}$ & $32.800,00 *$ & $29.811,00 * *$ & $29.811,00 * *$ & $29.811,00 * *$ \\
\hline Valor médio p/ há/ano (1 x2) (50\% Transf) & 0,22 & 1,90 & 0,52 & 2,38 \\
\hline \multicolumn{5}{|c|}{ Porto Ferreira } \\
\hline & 1995 & 1996 & 1997 & 1998 \\
\hline Arrecadação ITR & $1.668,24$ & $17.274,84$ & $8.062,51$ & $17.772,41$ \\
\hline Hectares totais & $22.077,40$ & $22.077,40$ & $22.077,4$ & $22.077,4$ \\
\hline Hectares tributáveis ${ }^{(3)}$ & $18.299,5^{*}$ & $17.204,4 * *$ & $17.204,4^{* *}$ & $17.204,4^{* *}$ \\
\hline Valor médio p/há/ano & 0,09 & 1,00 & 0,47 & 1,03 \\
\hline
\end{tabular}

(1)*Corresponde a $73,9 \%$ da área rural do município. ** Corresponde a $71,3 \%$ da área total rural do município.

(2)*Corresponde a 79,1\% da área rural do município. ** Corresponde a 70,2\% da área rural do município.

(3) *Corresponde a $82,9 \%$ da área rural do município. ** Corresponde a 77,9\% da área rural do município.

Fonte: FIBGE (1985, 1996)/ Secretaria do Tesouro Nacional -STN (1999)/ PINO (1996) /Dados da pesquisa, 1998.

Tabela 3 - Arrecadação e Projeção do imposto territorial rural (ITR) - Bragança Paulista - SP. 1995/1998 (R\$)

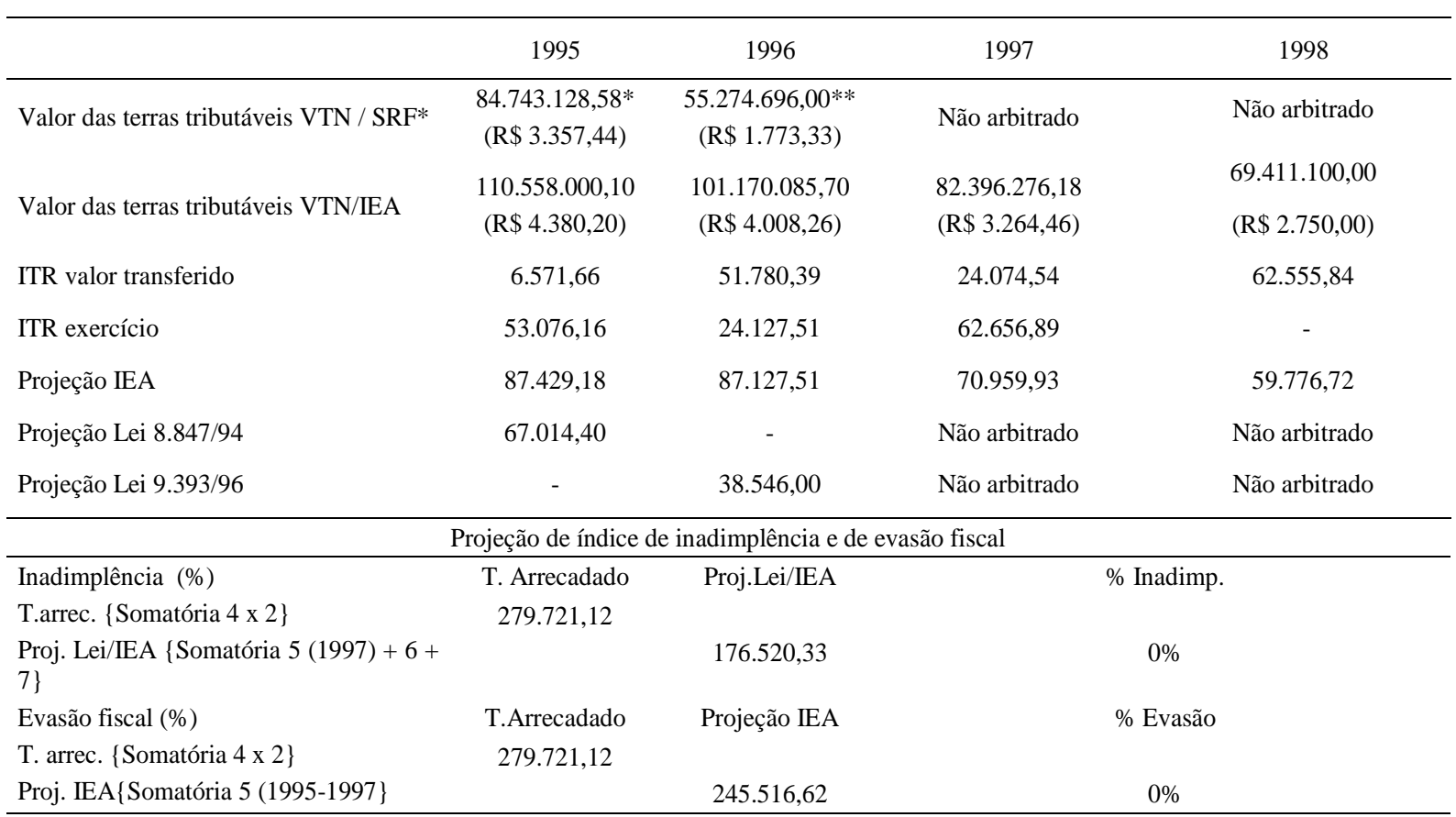

* VTN/SRF/1995 - R \$ 3.357,44** VTN/SRF $1996-\mathrm{R} \$ 1.773,33$.

Fonte: Secretaria do Tesouro Nacional -STN (1999)/ PINO (1996)/Dados da pesquisa, 1998. 
tributável em torno de $10 \%$ do total, considerando que os $20 \%$ restantes seriam destinadas à preservação e não estariam passíveis de tributação. Acrescente-se que os valores pagos por hectare são extremamente baixos se comparados aos tributos territoriais urbanos, apesar de se conceber um aumento significativo na arrecadação do imposto.

No município de Franca, os valores arrecadados apresentam evolução positiva, mas assim como em Bragança Paulista, a redução do VTNm não permite indicar um grau de inadimplência; por outro lado, dada a apuração dos dados do IEA, conseguiuse identificar um percentual de evasão em torno de $18 \%$ (Tabela 4); se computados os mesmos fatores que reduzem a base de cálculo (exclusão das propriedades com menos de $30 \mathrm{ha}$ - segunda classe de área do município - e a homogeneização do VTN do município sede), estes índices chegariam a patamares bem mais expressivos. A tabela 3 indica a oscilação nos valores arrecadados: total e por hectare.

Ao analisar esse município também se verifica a renúncia fiscal da União ao reduzir em torno de $69,4 \%$ o VTNm no ano de 1996 (Tabela 4), isto se comprova nos dados indicados na Tabela 3, para as transferências de 1997, quando o valor arrecadado por ha apresenta uma redução de $73 \%$.

A análise dos dados do município de Porto Ferreira (Tabela 3 e 5) permite apontar para um índice de inadimplência da ordem de $31 \%$. Nesse caso, existem dois fatores que auxiliam na explicação desse índice para Porto Ferreira: a) os municípios menores apresentam em seu entorno pequenas propriedades cuja função e ou forma de exploração é quase que exclusivamente agrícola, reduzindo-se as áreas com função de "chácaras de recreio" mais comuns no entorno de grandes centros urbanos (Bragança Paulista, por exemplo). Ao ter esta configuração, na grande maioria, os proprietários ocupam o local com trabalho e moradia, o que integra grande parte destas áreas nos conceitos de imunidade e isenção do ITR. Essa forma de ocupação, exclusiva do proprietário, com reduzido absenteísmo, faz com que as pequenas propriedades sejam efetivamente englobadas nas áreas de isenção, o que não altera em muito a base de cálculo, conforme aponta a Instrução Normativa/SRF nº 43 (07/ 05/1997); b) observa-se que esta classe de área no município de Porto Ferreira, até 50 ha, representa a terceira grandeza, o que caracteriza menor grau de importância no quadro fundiário.

No que se refere aos outros aspectos de renúncia fiscal tendo em vista a redução dos valores da VTNm, o município apresenta as mesmas características, a evasão fiscal atinge 52\%, o maior índice em comparação aos municípios estudados, ainda que ocorra uma evolução positiva na arrecadação do imposto territorial rural (Tabela 5).

Tabela 4 - Arrecadação e Projeção do ITR - Franca - 1995/1998 (R\$)

\begin{tabular}{|c|c|c|c|c|}
\hline & 1995 & 1996 & 1997 & 1998 \\
\hline $\begin{array}{l}\text { Valor das terras tributáveis VTN / } \\
\text { SRF* }\end{array}$ & $\begin{array}{l}75.900 .840,00 * \\
(\mathrm{R} \$ 2.314,05)\end{array}$ & $\begin{array}{c}30.074 .231,13 * * \\
(\mathrm{R} \$ 1.008,81)\end{array}$ & Não arbitrado & Não arbitrado \\
\hline Valor das terras tributáveis VTN/IEA & $\begin{array}{l}82.923 .976,00 \\
(\mathrm{R} \$ 2.528,17)\end{array}$ & $\begin{array}{l}79.333 .629,42 \\
(\mathrm{R} \$ 2.661,22)\end{array}$ & $\begin{array}{l}44.962 .738,86 \\
(\mathrm{R} \$ 1.508,26)\end{array}$ & $\begin{array}{l}52.169 .250,00 \\
(\mathrm{R} \$ 1.750,00)\end{array}$ \\
\hline ITR valor transferido & $3.567,61$ & $28.280,24$ & $7.649,66$ & $35.504,20$ \\
\hline ITR exercício & $21.919,23$ & $14.276,96$ & $36.038,78$ & - \\
\hline Projeção IEA & $62.971,02$ & $72.248,50$ & $40.947,21$ & $47.510,12$ \\
\hline Projeção Lei 8.847/94 & $57.637,18$ & - & - & - \\
\hline Projeção Lei 9.393/96 & - & $27.388,36$ & - & - \\
\hline
\end{tabular}

\begin{tabular}{|c|c|c|c|}
\hline \multicolumn{4}{|c|}{ Projeção de índice de inadimplência e de evasão fiscal } \\
\hline Inadimplência $(\%)$ & T. Arrecadado & Projeção Lei/IEA & \% Inadimplência \\
\hline \multicolumn{4}{|l|}{ T. arrec. $\{$ Somatória $4 \times 2$ × } \\
\hline $\begin{array}{l}\text { Proj. lei/IEA \{Somatória } 5(1997)+6 \\
+7\}\end{array}$ & $144.469,94$ & $125.972,75$ & $0 \%$ \\
\hline Evasão fiscal (\%) & T.Arrecadado & Projeção IEA & \% Evasão \\
\hline T. arrec. $\{$ Somatória 4 x 2 \} & \multirow{2}{*}{$144.469,94$} & \multirow{2}{*}{$176.166,73$} & \multirow{2}{*}{$18,0 \%$} \\
\hline Proj. IEA \{Somatória 5 - 1995/1997\} & & & \\
\hline
\end{tabular}

* VTN/SRF-1995 - R \$2.314,05 ** VTN/SRF 1996 - R \$ 1.008,83.

Fonte: Secretaria do Tesouro Nacional -STN (1999)/ PINO (1996) /Dados da pesquisa, 1998.

Ciência Rural, v.34, n.5, set-out, 2004. 
Tabela 5 - Arrecadação e projeção do imposto territorial rural (ITR) - Porto Ferreira - SP. 1995/1998- (R\$)

\begin{tabular}{|c|c|c|c|c|}
\hline & 1995 & 1996 & 1997 & 09/1998 \\
\hline Valor das terras tributáveis VTN / SRF* & $\begin{array}{l}60.494 .304,11^{*} \\
(\mathrm{R} \$ 3.305,79)\end{array}$ & $\begin{array}{l}26.034 .386,26^{* * *} \\
(\mathrm{R} \$ 1.513,24)\end{array}$ & - & - \\
\hline Valor das terras tributáveis VTN/IEA & $\begin{array}{l}80.155 .469,90 \\
(\mathrm{R} \$ 4.380,20)\end{array}$ & $\begin{array}{l}68.959 .192,21 \\
(\mathrm{R} \$ 4.008,23)\end{array}$ & $\begin{array}{l}56.163 .075,62 \\
(\mathrm{R} \$ 3.264,46)\end{array}$ & $\begin{array}{l}40.143 .542,65 \\
(\mathrm{R} \$ 2.333,33)\end{array}$ \\
\hline ITR valor transferido & $1.668,24$ & $17.274,84$ & $8.062,51$ & $17.772,41$ \\
\hline ITR exercício & $11.223,40$ & $14.051,33$ & $17.952,49$ & - \\
\hline Projeção IEA & $66.297,65$ & $63.075,18$ & $51.370,52$ & $36.717,98$ \\
\hline Projeção Lei 8.847/94 & $50.035,21$ & - & - & - \\
\hline Projeção Lei 9.393/96 & - & $23.812,80$ & - & - \\
\hline \multicolumn{5}{|c|}{ Projeção de índice de inadimplência e de evasão fiscal } \\
\hline Inadimplência (\%) & T. arrecadado & Projeção lei/IEA & \% Inadimplência & \\
\hline T. arrec. $\{$ Somatória $4 \times 2\}$ & $86.454,44$ & & & \\
\hline Proj. Lei/IEA $\{$ Somatória 5(1997) + $6+7\}$ & & $125.218,53$ & $31 \%$ & \\
\hline Evasão fiscal (\%) & T. Arrecadado & Projeção IEA & \% Evasão & \\
\hline T. arrec. $\{$ Somatória 4$\}$ & $86.454,44$ & & & \\
\hline Proj. IEA \{Somatória 5 1995-1997\} & & $180.743,35$ & $52 \%$ & \\
\hline
\end{tabular}

* VTN/SRF - 1995 - R \$ 3.305,79. ** VTN/SRF $1996-\mathrm{R} \$ 1.008,83$.

Fonte: Secretaria do Tesouro Nacional -STN (1999)/ PINO (1996)/Dados da pesquisa, 1998.

\section{CONCLUSÃO}

Verificou-se que o ITR apresenta reduzido impacto na composição das receitas municipais reduzindo seu perfil de participação ao longo do período analisado e que as projeções de arrecadação com base nos valores da terra nua pesquisados pelo Instituto de Economia Agrícola (IEA), poderiam promover resultados significativos na arrecadação do tributo. O que se destaca como fundamental em todo este processo é que do ponto de vista do impacto na composição das receitas municipais o tributo reduz seu grau de importância e que apesar dos setores progressistas terem provocado intenso debate sobre o papel social da propriedade rural, a elaboração de uma política fiscal com objetivos de atingir o grau de utilização da terra e a capacidade contributiva do setor, os avanços provocados com o aumento da alíquota ficaram visivelmente diluídos na redução do VTNm e que a SRF ao deixar de arbitrar um valor mínimo para a terra nua, a partir de 1997, tornou o tributo totalmente declaratório e promoveu uma efetiva renúncia fiscal.

\section{REFERÊNCIASBIBLIOGRAFICAS}

ARAÚJO, A.B. et al. Transferências de impostos aos estados e municípios. Rio de Janeiro : IPEA/INPES, 1972. 272p. (Coleção Relatório de Pesquisas, 16).

DALTON, H. Principles of public finance. London : Routledge \& Kegan Paul, 1954. 237p.
FARIAS, F.M.G. As perspectivas do ITR na administração da SRF. Fortaleza : DRRF/SRF 1994. 57p. (mimeografado).

FIBGE CENSO AGROPECUÁRIO - SÃO PAULO. (vários volumes de1960, 1970, 1985 e 1996).

INSTITUTO DE ECONOMIA AGRÍCOLA - ANUÁRIO DE INFORMAÇÕES ESTATÍSTICAS DA AGRICULTURA. São Paulo: IEA. SÉRIE INFORMAÇÕES ESTATÍSTICAS DA AGRICULTURA. (Vários exemplares de 1993 a 1998).

INTERNATIONAL MONETARY FUND - Brazil: issues for fundamental tax reform. Washington : Fiscal Affairs Department/IMF, 1992. 179p.

JOBIM, N. A. et al. A exposição de motivos da emenda constitucional da reforma tributária. O Estado de São Paulo, ed. 24.08.95. p.A2.

KANDIR, A. Reforma tributária, federalismo e globalização. Folha de São Paulo, ed. 15.09.95. p.A2.

PINO, F.A. (org.). Levantamento Censitário de Unidades de Produção Agrícola do Estado de São Paulo. São Paulo: IEA/CATI/SAA/1996. 4v.

REZENDE, F. Federalismo Fiscal no Brasil. Revista de Economia Política. São Paulo, v.15. n.3. p.5-17, jul/set, 1995.

SECRETARIA DO TESOURO NACIONAL (STN). Relatórios de Arrecadação. Brasília, DF : STN, 1999. 320p.

SOUZA, J.G. Reforma com ITR. Suplemento Agrícola - O Estado de São Paulo, ed. 15.11.95. Artigos p.2.

VILARINHO, C.R.O. O imposto territorial rural (ITR) no Brasil. 1989. 258f. Dissertação (Mestrado em Economia) - Curso de Pós-graduação em Economia, Universidade Estadual de Campinas. 